\title{
Putting environmental technologies into the mainstream: Adoption of environmental technologies by medium-sized manufacturing firms in Brazil
}

\author{
Gabriel Cepollaro Diana ${ }^{\mathrm{a}}$, Charbel José Chiappetta Jabbour ${ }^{\mathrm{a}}{ }^{\mathrm{b}}$, \\ Ana Beatriz Lopes de Sousa Jabbour ${ }^{\text {a, c }}$, Devika Kannan d, * \\ ${ }^{a}$ UNESP - Sao Paulo State University, Production Engineering Department, Av. Eng. Carrijo Coube, 14-01, DEP-FEB, Bauru, SP, Brazil \\ ${ }^{\mathrm{b}}$ University of Stirling, Stirling Management School, Stirling, Scotland FK9 4LA, UK \\ ${ }^{c}$ University of Strathclyde, Faculty of Engineering, DMEM, 75 Montrose St, Glasgow G1 1XJ, UK \\ ${ }^{\mathrm{d}}$ University of Southern Denmark, Centre for Engineering Operations Management, Department of Technology and Innovation, Denmark
}

\section{A R T I C L E I N F O}

\section{Article history:}

Received 21 December 2015

Received in revised form

30 August 2016

Accepted 13 October 2016

Available online 31 October 2016

\section{Keywords:}

Environmental technologies

Critical success factors

Sustainable operations

Sustainability

Small and medium enterprises

\begin{abstract}
A B S T R A C T
The aim of this research is to analyze how critical success factors (CSFs) can influence the adoption of environmental technologies by Brazilian manufacturing companies. In terms of conceptual background, this research fits within the context of environmental management in organizations, focusing on the adoption of environmental technologies in the manufacturing context and their critical success factors. In terms of methodology, this research is based on a case study conducted on two medium-sized industrial companies located in Brazil (company "Alfa" and company "Beta"). The results show the emergence of a new CSF called employee empowerment, which derives from learning and benchmarking initiatives. Two CSFs can be highlighted as the most relevant and unanimously present in both company "Alpha" and company "Beta": support from senior management and employee empowerment through learning and benchmarking. In addition, communication and cultural organizational changes were relevant CSFs, especially for Beta. Furthermore, there is a potential synergistic relationship between CSFs and the maturity level of environmental management. For example, Beta was on a more advanced environmental level as well as had greater intensity in terms of CSFs than Alpha. This work can be considered one of the first researches relating CSFs and the adoption of environmental technologies in medium-sized firms in Brazil.
\end{abstract}

๑) 2016 Elsevier Ltd. All rights reserved.

\section{Introduction}

Given the importance of environmental constraints challenging society (Hackmann et al., 2014), it is important that manufacturing companies innovate and modify their management toward greener manufacturing, as manufacturing processes tend to consume great amounts of energy and materials (Liu et al., 2016; Le Bourhis et al., 2013). Actually, several authors have reaffirmed the central role manufacturing plays in the process of "greening" organizations (Dornfeld, 2014; Govindan et al., 2015). This new manufacturing context, also called "sustainable operations management" (Walker et al., 2014), requires the adoption of environmental technologies,

\footnotetext{
* Corresponding author.

E-mail address: deka@iti.sdu.dk (D. Kannan).
}

as defined by Kuehr (2007). The improvement of environmental conditions through the adoption of environmental technologies and innovations is supported by the theoretical and analytical current of ecological modernization, which claims the possibility of combining environmental legislation, cleaner industrial innovation, and improvement of companies' environmental performance (Sarkis et al., 2011). Within this context the adoption of environmental technologies is part of an emerging concept of world-class, sustainable manufacturing (Dubey et al., 2015).

However, there may be a gap between the theoretical/conceptual assumptions and the effective implementation of green practices in Brazilian companies (Jabbour et al., 2016). Consequently, it is important to know the critical success factors (CSFs) (Freund, 1988) that can be prioritized by companies that are indeed wishing to adopt environmental technologies. On the other hand, a significant gap also persists in the state-of-the-art literature: 
systematic searches using the keywords corresponding to this present work, carried out on the ISI-Web of Science and Scopus databases, revealed a lack of studies on CSFs for the adoption of environmental technologies in general, as the majority of the works focused on CSFs for green management, not CSFs for environmental technology adoption. An additional gap was observed: only studies that do not portray the reality in Brazil were identified, highlighting the relevance for studying Brazilian cases:

- Bartlett and Trifilova (2010), based on the Russian reality, proposed that collaboration is essential for fostering the development of environmental technologies. Similar results were proposed by Fernando et al. (2016) in the Malaysian context.

- Subramanian et al. (2013) discovered that Chinese firms are unlikely to embark on reverse logistics without external critical factors, such as strict governmental legislation.

- Medeiros et al. (2014) proposed four main critical success factors for environmentally sustainable product innovation: market, law, and regulation knowledge; interfunctional collaboration; innovation-oriented learning; and research \& development (R\&D) investments.

- Diabat and Govindan (2011) highlighted governmental regulation and reverse logistics as CSFs for the adoption of green supply chain practices and related technologies in India.

- Lin and Ho (2011) analyzed the adoption of green practices by Chinese logistic firms. They discovered the following CSFs: organizational support, human resources, regulatory pressure, and governmental support.

- Hu and Hsu (2010) studied the adoption of green supply chain practices and technology in electronic industries in Taiwan. They found four dimensions of critical factors: supplier management, product recycling, organization involvement, and lifecycle management.

- Wee and Quazi (2005) studied companies in Singapore. They discovered seven CSFs for adopting environmental management systems, such as top management, employee involvement, and training, among others.

- Johansson (2002) declared CSFs for eco-design adoption. The most relevant CSFs were competence (training, environmental specialist, best practices) and motivation (green mind-set, green champions, employee involvement).

From this context the main concern of this research arises: What are the critical success factors (CSFs) that may influence the adoption of environmental technologies in manufacturing companies, and how do they act? Thus, this research's main objective is to analyze, through exploratory case studies, how critical success factors (CSFs) influence the adoption of environmental technologies by Brazilian manufacturing companies.

This present work is a qualitative research based on exploratory case studies because: (1) a better understanding of the surrounding conditions to improve the environmental management of companies in developing countries is an emerging issue (Gunasekaran et al., 2014); (2) quantitative research on this subject has already been conducted, although there are still opportunities for more qualitative detailing (Dornfeld, 2014; Govindan et al., 2015); and (3) in general, more qualitative research is being encouraged by scholars of sustainable operations management (Pagell and Shevchenko, 2014).

The main aims of this work are:

- To explore an understudied field of research (i.e., the relationship between CSFs and the adoption of environmental technologies in manufacturing firms);
- To shed light on the reality of Brazilian companies by providing an exploratory and qualitative study, as more empirical research in Latin America is necessary (Liston-Heines and Vazquez-Brust, 2016), especially in Brazil (Abreu, 2009);

- To identify the CSFs that should be correctly managed in order to promote the adoption of environmental technologies, taking into account that small and medium firms in Brazil should be better understood (Godinho Filho et al., 2016); and

- To highlight the emergence of employees' empowerment as a CSF based on leveraged learning and benchmarking.

This work is organized as follows. Section 2 shows the conceptual foundations (environmental management, environmental technologies, and critical success factors). Section 3 describes the research methodology. Section 4 shows the research results, followed by discussions (Section 5) and conclusions (Section 6).

\section{Conceptual background}

\subsection{Green manufacturing}

Cutting-edge concepts and practices, such as "sustainable operations management" (Walker et al., 2014) and "carbon-efficient production" (Tiwari et al., 2015), have environmental management at their core. Environmental management can be defined as the attention to, and adoption of, principles, environmentally supportive practices and technologies, waste-reduction initiatives, and improvement of firms' social responsibility, which can possibly bring greater corporate competitive edge (Haden et al., 2009). Jabbour (2010) complemented this definition by pointing out that environmental management should be addressed systemically, thus implementing environmental practices at all levels of a company. In the ecological modernization field, it is alleged that environmental law, environmental technology innovation, and improvement of the environmental performance of companies are able to coevolve (Sarkis et al., 2011).

One should also consider the degree of commitment of a company in relation to the environment. This demonstrates the commitment this company has to environmental management. The level of commitment is also referred to as the evolutionary stage or maturity level of environmental management (Jabbour and Jabbour, 2013). For this research, three stages are considered.

The reactive stage of environmental management, wherein environmental management is deemed unnecessary, is the least developed stage. The senior management team is not concerned about and gives little support to actions related to environmental management because the barriers are prominent and the benefits have not been realized. Thus, companies tend to react only to emergent challenges.

The preventive stage of environmental management is considered an intermediate stage. In this stage companies begin to anticipate problems related to environmental issues. The prospect of the benefits that environmental management can bring about is more optimistic and deserves more attention from the senior management team.

The proactive stage of environmental management is the most evolved of the stages. At this point there is a strong commitment from the senior management team to enable the implementation of environmental projects. Environmental management becomes a clear organizational area/function in a firm's hierarchy and creates positive impacts on other organizational areas (Prajogo et al., 2014). In this context environmental management starts creating synergy with others managerial trends, such as supply chain management (Liu et al., 2016). The adoption of environmental management tools, such as ISO 14001 (Campos et al., 2015) also occurs, and thus, the 
benefits of environmental management tend to be better noticed. Environmental technologies tend to be adopted intensely.

\subsection{Environmental technology}

The term "environmental technology" still has a very broad definition. Several studies (Vachon and Klassen, 2007; Kuehr, 2007) have mentioned this term and tried to define it; even so, there is still little clarity, and there are conceptual gaps to be filled. One definition involving all of the previous definitions and complementing them was proposed. According to Jabbour (2010), based on Kuehr (2007), environmental technology is the development of hardware and software that, by adopting new design concepts, operating equipment, and procedures, starts to incorporate practices for continuous improvement of the company's environmental performance, mainly by using raw materials that have low environmental impact, processing them efficiently, and promoting reutilization and minimal waste of their final products, thus changing the products and processes of a given production cycle.

Environmental technologies provide the opportunity to be strategic resources for firms mainly because they may offer unique and original competitive advantages. Adopting environmental technologies may allow companies to have a better product portfolio, improving eco-efficiency across the company and across the supply chain. As a consequence, companies tend to gain a better competitive advantage (Shrivastava, 1995).

A study conducted by Kuehr (2007) stands out for classifying environmental technologies. This author created a typology that is divided into categories. The first category is that of environmental measurement technologies, which do not address the minimization of anthropogenic impacts on the environment but instead measure data for understanding such impacts; the second category is that of end-process technologies, which are based on solutions for the end of the line, using, for instance, catalysts or filters, but which, on the other hand, bring about higher energy consumption costs; the third category is that of cleaner technologies, which are based on changes in production processes or the raw materials used and have an integrated view of the production cycle in order to minimize end costs and consumption losses; the fourth and final category is that of clean or no-impact technologies, which have no impact on the environment but, unfortunately, are considered quite utopian.

Some relevant findings on the development and adoption of environmental technologies can be highlighted. Klassen and Whybark (1999) conducted research on the relationship between the adoption of environmental technologies and environmental performance. They discovered that companies adopting moreadvanced environmental management tend to invest in pollutionprevention technologies. Fernando et al. (2016) and Bartlett and and Trifilova (2010) affirmed that developing environmental technologies requires strong collaboration, both internally and externally to organizations.

Thus, it is believed that the adoption of such environmental technologies in the context of organizational environmental management is influenced by critical success factors (CSFs), according to studies that address this issue (Subramanian et al., 2013).

\subsection{Critical success factors for environmental technology adoption}

Critical success factors (CSFs) are essential aspects of firms' greening. A company that observes these factors properly and works with a proactive environmental management approach will observe lower resistance from stakeholders (employees, suppliers, etc.) in the implementation of environmental technologies, and therefore, the implementation will be successful, which makes for a smoother, faster, more effective, and more sustainable process (Zutshi and Sohal, 2004). Some critical success factors that are considered the most relevant to this research are briefly described below.

One of the pioneering studies on CSFs was conducted by Rockart (1978), who define critical success factors as key aspects that must be properly managed and must occur in the best possible way in order to make the business flourish. In other words, CSFs are the limited number of organizational aspects where the results, if satisfactory, ensure competitive success and better performance for the organization. Aligned with this view, it is possible to argue that "CSFs are those few things that must go well to ensure success for a manager or an organization, and, therefore, they represent those managerial or enterprise areas that must be given special and continual attention to bring about high performance" (Boynton and Zmud, 1984).

Because of the relevance of CSFs as a field of research, a large variety of disciplines have incorporated CSFs as a subject, such as lean manufacturing (Achanga et al., 2006), R\&D project management (Pinto and Slevin, 1989), green building (Lam et al., 2010), information technology (Umble et al., 2003), and reverse logistics (Mangla et al., 2016).

The field of green management has also considered CSFs an important subject. Subramanian et al. (2013) pointed out that Chinese enterprises are unlikely to go ahead with reverse logistics without key external critical factors, such as strict governmental legislation. Medeiros et al. (2014) proposed four main critical success factors for environmentally sustainable product innovation: market, law, and regulation knowledge; interfunctional collaboration; innovation-oriented learning; and $R \& D$ investments. Diabat and Govindan (2011) highlighted governmental regulation and reverse logistics as CSFs for the adoption of green supply chain practices and related technologies in India. Lin and Ho (2011) analyzed the adoption of green practices by Chinese logistic firms and discovered the following CSFs: organizational support, quality of human resources, regulatory pressure, and governmental support. Hu and Hsu (2010) studied the adoption of green supply chain practices and technology in electronic industries in Taiwan; they found four dimensions of critical factors: supplier management, product recycling, organization involvement, and life-cycle management. Wee and Quazi (2005) studied companies from Singapore; they discovered seven CSFs for adopting environmental management systems, such as top management, employee involvement, and training, among others. Johansson (2002) declared the CSFs for eco-design adoption. The most relevant CSFs were competence (training, environmental specialist, best practices) and motivation (green mind-set, green champions, employee involvement). Jabbour et al. (2015) highlighted, based on evidence from Brazilian companies, that human CSFs are essential for adopting low-carbon eco-innovations. Finally, developing environmental technology requires internal and external collaboration (Bartlett and Trifilova, 2010; Fernando et al., 2016).

Based on the aforementioned literature review, the first factor to consider is the support from senior management (Wee and Quazi, 2005). Senior management's commitment is of utmost importance to ensure the concern for, and understanding of, environmental issues. This commitment is crucial in the adoption, implementation, and maintenance of a new technology. Learning about environmental issues is the first step for the senior management team to take on such a commitment and provide the subsequent support. Some ways top managers can make a positive impact on their organizations include providing leadership and motivation to all levels of staff; providing aid to implementation; and allocating time for communication, training, and motivation during the implementation phases. However, for senior managers 
to reach that level of understanding and provide support for environmental issues, they must be aware of the positive returns and benefits the new technology will bring to the company and its stakeholders. Moreover, top managers must be aware of the responsibilities the organization has in relation to environmental issues and possible accidents.

A very important factor is environmental training (Renwick et al., 2016). Organizations must provide their employees with training in order to have them up to date with the new measures being implemented. Training is an important element for empowering green teams (Dangelico, 2015). As a result, all levels of the organization will be able to contribute to the successful implementation of either environmental technologies or new practices (Teixeira et al., 2012).

An additional important factor that should be considered is cultural and organizational change (Jabbour et al., 2015). This factor is as important as the support from the senior management team because it involves all levels of the organization's employees, with a new vision of the organization in relation to environmental management issues.

In this regard it is necessary to consider the importance of communication so that there is an effective cultural change (Wee and Quazi, 2005). For all levels of the company's employees to be aware of the new positioning of the company, it is crucial to have communication and exchange of information among all the parties involved, that way everyone will know the benefits the new environmental technology will bring to the organization as well as the steps for its successful implementation. Additionally, communication between stakeholders, both internal and external, will allow them to contribute to the implementation and its maintenance.

Learning from the experiences of other organizations and benchmarking can also be regarded as critical success factors (Wee and Quazi, 2005). Learning from other companies' experiences can help a company to reduce potential challenges and obstacles since it will already be aware of these challenges and prepared for each of them. Learning by benchmarking can help a company to identify best practices and ways to implement a practice, new technology, or new environmental management system.

\section{Research methodology}

Because this subject has been little explored, an exploratory study of multiple cases was carried out since this type of research approach is recommended when the subject is still mostly conceptual (Teixeira et al., 2012). Having a qualitative approach, two case studies were conducted, aiming at a deeper analysis of the topic. Although the quantity of cases may be considered limited, it is aligned with the quantity of cases considered acceptable by scholars in the sustainability field of research (Anholon et al., 2016; Giannetti et al., 2008).

As a minimum requirement, the companies selected needed to have the ISO 14001 certification. About seven companies in the great industrial central area of Sao Paulo state, Brazil, met this minimum requirement. Services firms, although relevant (Wong et al., 2013), were discarded due to the nature of this work. The central region is a major industrial area in Sao Paulo, which is the most industrialized and relevant state in Brazil (Duarte et al., 2011). Studying Brazil can be justified because of the necessity of knowing more about environmental management in Latin America (ListonHeines andVazquez-Brust, 2016) and in emerging economies (Abreu, 2009; Geng and Doberstein, 2008). Contact via email and telephone was made with all seven firms; nevertheless, only two (hereafter called "Alpha" and "Beta") agreed to receive an on-site visit and be involved in an in-depth analysis, thus characterizing the case study methodology.
Data collection involved in-depth interviews of environmental and production managers from Alpha and the environmental manager of Beta, who is also head of quality and safety issues in the environmental department. The interviews were divided into two parts, each with a manager, but in the case of Beta, the manager who was interviewed answered the whole set of questions. Interviews and site visits occurred between October 2013 and January 2014. Table 1 shows some characteristics of the companies. The interviews' main subjects were new environmental technologies adopted by the companies, the role of critical success factors, and the level of environmental management pursued by the companies.

\section{Research results}

\subsection{Alpha}

Alpha had been working with an environmental management system since 1993, with the creation of its environmental management department. ISO 9001 was implemented in 2000, and ISO 14001 was implemented in 2006. This company claims to have created this department considering not only its necessity but also financial, trading, and environmental terms.

This company has implemented a number of environmental technologies and adopted many environmental practices throughout its history, even before the accomplishment of ISO 14001. During the interviews many environmental technologies were mentioned, such as the adoption of filters and an exhaust system, which were installed and implemented by a third party; internal care with air-conditioning and maintenance; and total recycling of batteries, among other practices. However, two technologies stood out as being subject to classification according to Kuehr (2007), as previously discussed. The first technology was the practice of remotely charging batteries, and the second technology was a new type of battery developed with expanded plates.

The first technology of remotely charging batteries was adopted because it is safer and reduces energy consumption. A machine carries out the initial charging of a battery remotely, without any human manipulation and with the exact amount of energy required for the battery. Previously this charging was performed manually by company employees and, thus, risked serious issues and energy waste since human error could occur in the process.

The second technology was applied on a new battery that was developed with expanded lead plates. This technology was acquired through an exchange/collaboration with European companies. These expanded plates brought increased productivity to the company along with new manufacturing practices, which were not mentioned by the respondent.

For both the technologies implemented, tests were performed in company laboratories owned by Alpha. Following the implementation decision, training of the teams involved was given in order to upgrade the teams and inform them of the new procedures that would be implemented and the steps involved in the process so that the implementation of the technology was successful.

It should be noted that the initial projects to adopt these technologies came from the senior management team and had their support throughout the implementation processes. For various purposes, such as export expansion, cost reduction, improved quality, and increased productivity, support from the senior management team was essential for the successful implementation of the technologies.

However, it was emphasized that employees were part of the process, seeking technologies and implementing them, and were equally encouraged to share their opinions regarding the way a process was occurring. Certain autonomy was given to the employees for them to change the process, provided it was for the 
Table 1

Summary of the characteristics of the companies analyzed.

\begin{tabular}{|c|c|c|c|}
\hline \multicolumn{2}{|c|}{ Company Description } & \multicolumn{2}{|l|}{ Dynamics of data collection } \\
\hline & & Respondents & Visits/Documents \\
\hline Alpha & $\begin{array}{l}\text { Brazilian company of the battery industry, located in } \\
\text { São Paulo, Brazil; classified as a medium-sized firm. }\end{array}$ & $\begin{array}{l}\text { Interview with the head of the environmental } \\
\text { management department. } \\
\text { Interview with the manager of the factory's } \\
\text { production area. } \\
\text { Complementary interviews were allowed. }\end{array}$ & $\begin{array}{l}\text { Visits to the factory were carried out. } \\
\text { The company's website provided the basic information for } \\
\text { choosing the case. }\end{array}$ \\
\hline Beta & $\begin{array}{l}\text { Brazilian company of the wood pulp sector, located } \\
\text { in São Paulo, Brazil; classified as a medium-sized } \\
\text { company in expansion. }\end{array}$ & $\begin{array}{l}\text { Interview with the manager and head of the } \\
\text { environmental department, quality and safety } \\
\text { in the workplace. } \\
\text { Complementary interviews were allowed. }\end{array}$ & $\begin{array}{l}\text { Visits to the factory were carried out. } \\
\text { The company's website provided the basic information for } \\
\text { choosing the case, as well as a report of detailed } \\
\text { environmental performance. }\end{array}$ \\
\hline
\end{tabular}

better; that is to say, if an employee found a better way to use the new technology, this way would be adopted by all, and if an improvement was actually verified, this employee would be rewarded. This is what in the management literature is referred to as "empowerment," a practice used in businesses nowadays. The production manager interviewed claimed that there were few challenges at the shop-floor level. The biggest challenges were technical problems, mainly one that occurred during the setup but that was then resolved by following the suggestion offered by an employee. Thus, employee empowerment was key.

\subsection{Beta}

In Beta, certification for ISO 14001 was accomplished before the ISO 9001 certification in 2008 and 2009, respectively. The company also has CSF certification, accomplished in 2006. This is a certificate that confirms that the forest operations carried out by the company are in accordance with the natural standards of forest management. Beta stated that the creation of its environmental management department was not only due to necessity but also because it was a matter of survival since environmental legislation has become more rigorous and competition has increased when taking into account environmental requirements.

Because this company is of the wood pulp sector, it was already concerned about the new legislation in force and had been making plans to implement new green technologies. This is verified by the fact that the ISO 14001 certification was accomplished prior to the ISO 9001 certification. Another factor that motivated the company to seek changes was a proposal from the senior management team to increase the plant's size because the wood pulp industry is growing. The respondent, who is head of the environmental management department, emphasized that the company has always had an environmental character and that all the implementation projects for new technologies are assessed by the environmental management department. The department conducts an analysis of environmental and sustainability issues to determine not only production gains but also environmental gains.

A very important environmental technology that has been implemented in the company's production process was mentioned by the responding environmental manager: electrostatic precipitators, devices that, according to the interviewee, are essential to the company's expansion. These electrostatic precipitators, which are defined as environmental control devices, were installed on the boilers to release lower quantities of particulate matter and lower amounts of odorous gases resulting from the burning of raw material in the boilers.

In order to implement this technology, there also was training for the employees and support from senior management. It was noted that, because the company had already been working with environmental management for some time, this had become part of the company's culture, and, according to the environmental manager who was interviewed, there was a "natural and easy implementation of ISO 14001." Beta, just like Alpha, is closely in contact with its staff, thus making them naturally engaged whenever there are new actions in the company. Moreover, there are awards for employees who accomplish goals. Another point to be emphasized is the fact that the ISO certifications were a result of the actions the company had already been practicing, and therefore, the environmental character of the company was already quite consistent, allowing employees to make decisions about environmental management.

\section{Discussion}

As for the environmental management of the two companies, one can infer that both Alpha and Beta already had a certain level of concern about environmental issues and had already been applying environmental management measures for some time-since before the creation of the environmental management department and even before the implementation of ISO 14001. These companies can be considered to be in agreement with the new greening scenario of industrial organizations, as suggested by Govindan et al. (2015).

Both companies pointed out that their environmental departments were created out of necessity and for market survival. However, Beta already had a greater environmental character, as was mentioned in the previous section. Thus, Beta can be considered more environmentally proactive than Alpha, following Jabbour and Jabbour (2013).

It can be said that both companies have benefited from environmental management practices and from the environmental technologies implemented. As exemplified by Jabbour and Jabbour (2013), the companies experienced lower operating costs as well as better performance in production based on green initiatives. In the implementation of ISO 14001, these companies established partnerships with suppliers that already complied with the requirements of the ISO, thus generating a chain of green supplies because, as the environmental manager of Alpha said, "just as our customers require us to comply with environmental standards, we will require our suppliers to do the same."

This shows a trend in environmental management toward a greener supply chain, as suggested by the literature (Sarkis et al., 2011). Beta had the benefit of anticipating the legislation that was yet to come, as mentioned by the manager who was interviewed. Both companies claimed to have a good relationship with Cetesb (Companhia de Tecnologia de Saneamento Ambiental-Environmental Sanitation Technology Company), which is the body responsible for controlling, surveilling, monitoring, and licensing pollution-generating activities in the state of São Paulo. "Whenever we have a question regarding a particular standard, we communicate with the Cetesb for clarification," said the environmental manager of Beta. 
In relation to the challenges faced by the companies in environmental management and implementation of technologies, only Alpha claimed to have had challenges with the implementation of ISO 9000 due to the organizational culture of the company, which was in transition. However, after the certification of ISO 9001, the company applied new practices, with changes in its organizational culture, and thus, the environmental manager claimed the implementation of ISO 14001 and the adoption of environmental technologies posed no challenges or obstacles to the success of the new practices. Beta, on the other hand, which had already been practicing environmental management, had a greener organizational culture. The environmental manager claimed that all the measures taken in relation to the environmental management department occurred naturally and posed no challenges or obstacles to their successful implementation.

Besides fitting and confirming the definition by Jabbour (2010), the technologies mentioned by the respondents can be classified according to Kuehr's typologies (Kuehr, 2007). The technologies pointed out-such as the expanded plates for batteries, the remote charging of batteries, and the electrostatic precipitators-can be classified as cleaner technologies that will have an effect on the production process. This kind of technology improves productivity and waste reduction, becoming a competitive advantage, confirming Shrivastava's (1995) arguments.

The critical success factors that were initially considered were support from the senior management team, environmental training, cultural and organizational change, importance of communication, learning from other organizations and benchmarking experiences. Some of these critical success factors were confirmed. Others were less relevant for the successful implementation of environmental technologies; however, they should not be discarded. Finally, some unexpected factors, which were extremely important for the successful adoption of environmental technologies, were also identified.

Alpha and Beta confirmed that support from the senior management team is vital for a new technology or new practice to be well implemented. Without this support, a new bottom-up technology will unlikely be implemented due to probable lack of resources or acceptance by the senior management team. Therefore,

Table 2

Intensity of the critical success factors.

Critical success factors
Support from senior management
Cultural and organizational changes
Empowmerment for employees
Label:

support from the senior management team can be considered the basis for successful implementation.

In the context of an environmental cultural change, environmental communication is one factor that was common to the two companies and confirmed by both. Having good internal communication involving all the levels in a company brings about benefits to the process of implementation and helps clearly establish the company's objectives and goals. External communication can also be extremely important. Involving the community and agencies responsible for environmental regulation is important in order to be updated and to update stakeholders regarding organizational changes. The expanded plate technology applied to the "Alpha" company's new battery is a European technology that was brought to the company through an exchange between companies of the same industry.

However, a factor that was pointed out by Beta is that of cultural change and organizational vision. A company whose environmental culture is solid probably makes use of environmental practices as well as technologies. This facilitates the implementation of any other practice or environmental technology that may be necessary, making the process easy, fast, and smooth.

Another factor confirmed by the two companies is the environmental training factor. Without the proper training of its staff, a company cannot make effective use of any environmental technology or practice adopted, and therefore, it will be useless and a waste of resources in the long run. Consequently, having all levels of the company aware of, and participate in, organizational changes is crucial for a successful implementation.

A factor related to the involvement of employees, but which was not expected, is the empowerment factor. Both companies proved to have their employees involved in the process of implementation and to have given them some autonomy to change the application of these technologies, as well as the opportunity to improve them. In this way the employees were motivated to work better and to better adapt to changes, and thus, satisfaction with the work performed was higher. Empowerment experiences emerged from opportunities where learning, knowledge exchange, and benchmarking took place. Thus, it is possible to propose a link between employees' empowerment and learning.

Table 2 shows a summary of the intensity of the critical success factors pointed out by each company.

After analyzing the two cases comparatively, the following points can be summarized:

- The emergence of a new CSF, called employee empowerment, derives from learning and benchmarking;

- Two CSFs can be highlighted as the most relevant and unanimously present in both Alpha and Beta: support from senior management and employee empowerment through learning and benchmarking;

- Communication and cultural organizational changes were relevant CSFs, especially for Beta; and

- There is a potential synergistic relationship between CSFs and the maturity level of environmental management. For example, Beta was positioned at a more advanced environmental level as well as had greater intensity in terms of CSFs than Alpha.

\section{Conclusions}

According to the results obtained in this research, there is more attention from companies regarding environmental issues, and they wish to upgrade and comply with the current legislation. To do so, companies must initially apply the measures contained in the ISO 9001 and ISO 14001 certificates and then implement new 
techniques and new environmental practices because the existence of environmental management within a company is a prerequisite for success. Companies must also be aware of and keep up with new environmental technologies that have been developed in their industry. By doing so, they will be able to enjoy the benefits these technologies and practices offer, as long as they are successfully implemented.

Therefore, in this scenario, knowing which factors will make a new technology successful is an advantage. By analyzing both companies, one can conclude that support from senior management and empowerment are the two most relevant CSFs for the desired success. However, one should not rely solely on the support from the senior management team but also on the support and understanding of the employees who will use and be empowered by the new technologies and practices. According to Alt et al. (2014), employees have unique knowledge of firms, which promotes environmental improvement. Finally, according to Klassen and Whybark (1999), developing more advanced environmental management requires companies to adopt pollution-prevention technologies, which are intensive in human knowledge. Thus, building a strategic link between human resources management and the adoption of environmental technologies may have a potential outcome for companies pursuing sustainability. This process requires companies' attention to an emerging management topic named green/sustainable and human resources management (Longoni et al., 2016; Renwick et al., 2016; Yusliza et al., 2015; Ehnert et al., 2015; Jackson et al., 2011). Additionally, firms adopting environmental technologies need to pay attention to cultural and organizational changes and communication.

This research aims to contribute as follows:

- It highlights the relevance of handling top management support and employee empowerment (through learning and benchmarking) when adopting environmental technologies in medium-sized firms.

- It suggests a potential synergistic effect among the considered CSFs.

- It contributes to the theory of greening industrial companies (Govindan et al., 2015) since it introduces Brazilian cases to a still-emerging field of study (Gunasekaran et al., 2014).

- It provides qualitative evidence that caters to contemporary suggestions on the sustainability of operations (Pagell and Shevchenko, 2014).

- It has implications for higher-education institutions that teach and research environmental technologies and that are searching for sustainability (Leal Filho et al., 2016).

These results and reflections should be considered in view of the inherent limitations of this research. First, the research results cannot be generalized to all Brazilian companies; the results are more aligned with the reality of medium firms operating in Sao Paulo, near the industrial area of Bauru. Finally, it is necessary to point out that, although acceptable (according to, for example, Giannetti et al., 2008), the quantity of cases explored in this work could be enlarged.

\section{References}

Abreu, M.C.S.D., 2009. How to define an environmental policy to improve corporate sustainability in developing countries. Bus. Strategy Environ. 18 (8), 542-556.

Achanga, P., Shehab, E. Roy, R., Nelder, G., 2006. Critical success factors for lean implementation within SMEs. J. Manuf. Technol. Manag. 17 (4), 460-471.

Alt, E., Díez-de-Castro, E.P., Lloréns-Montes, F.J., 2014. linking employee stakeholders to environmental performance: the role of proactive environmental strategies and shared vision. J. Bus. Ethics 1-15 in press.

Anholon, R., Quelhas, O.L.G., Leal Filho, W., de Souza Pinto, J., Feher, A., 2016 Assessing corporate social responsibility concepts used by a Brazilian manufacturer of airplanes: a case study at Embraer. J. Clean. Prod. 135, 740-749. Bartlett, D., Trifilova, A., 2010. Green technology and eco-innovation: seven casestudies from a Russian manufacturing context. J. Manuf. Technol. Manag. 21 (8), 910-929.

Boynton, A.C., Zmud, R.W., 1984. An assessment of critical success factors. Sloan Manag. Rev. 25 (4), 17-27.

Campos, L.M., de Melo Heizen, D.A., Verdinelli, M.A., Miguel, P.A.C., 2015. Environmental performance indicators: a study on ISO 14001 certified companies. J. Clean. Prod. 99, 286-296.

Dangelico, R.M., 2015. Improving firm environmental performance and reputation: the role of employee green teams. Bus. Strategy Environ. 24 (8), 735-749.

Diabat, A., Govindan, K., 2011. An analysis of the drivers affecting the implementation of green supply chain management. Resour. Conserv. Recycl. 55 (6), 659-667.

Dornfeld, D.A., 2014. Moving towards green and sustainable manufacturing. Int. J. Precis. Eng. Manuf. Green Technol. 1 (1), 63-66.

Duarte, A.L.D.C.M., Brito, L.A.L., Di Serio, L.C., Martins, G.S., 2011. Operational practices and financial performance: an empirical analysis of Brazilian manufacturing companies. BAR Braz. Adm. Rev. 8 (4), 395-411.

Dubey, R. Gunasekaran, A., Chakrabarty, A., 2015. World-class sustainable manufacturing: framework and a performance measurement system. Int. J. Prod. Res. 53 (17), 5207-5223.

Ehnert, I., Parsa, S., Roper, I., Wagner, M., Muller-Camen, M., 2015. Reporting on sustainability and HRM: a comparative study of sustainability reporting practices by the world's largest companies. Int. J. Hum. Resour. Manag. 1-21 in press.

Fernando, Y., Wah, W.X., Shaharudin, M.S., 2016. Does a firm's innovation category matter in practising eco-innovation? Evidence from the lens of Malaysia companies practicing green technology. J. Manuf. Technol. Manag. 27 (2), 208-233. Freund, Y.P., 1988. Critical success factors. Plan. Rev. 16 (4), 20-23.

Geng, Y., Doberstein, B., 2008. Greening government procurement in developing countries: building capacity in China. J. Environ. Manag. 88 (4), 932-938.

Giannetti, B.F., Bonilla, S.H., Silva, I.R., Almeida, C.M.V.B., 2008. Cleaner production practices in a medium size gold-plated jewelry company in Brazil: when little changes make the difference. J. Clean. Prod. 16 (10), 1106-1117.

Godinho Filho, M., Ganga, G.M.D., Gunasekaran, A., 2016. Lean manufacturing in Brazilian small and medium enterprises: implementation and effect on performance. Int. J. Prod. Res. 1-23.

Govindan, K., Diabat, A., Madan Shankar, K., 2015. Analyzing the drivers of green manufacturing with fuzzy approach. J. Clean. Prod. 96, 182-193.

Gunasekaran, A., Jabbour, C.J.C., Jabbour, A.B.L., 2014. Managing organizations for sustainable development in emerging countries: an introduction. Int. J. Sustain. Dev. World Ecol. 21 (3), 195-197.

Hackmann, H., Moser, S.C., Clair, A.L., 2014. The social heart of global environmental change. Nat. Clim. Change 4 (8), 653-655.

Haden, S.S.P., Oyler, J.D., Humphreys, J., 2009. Historical, practical, and theoretical p3w4pectives on green management: an exploratory analysis. Manag. Decis. 47 (7), 1041-1055.

Hu, A.H., Hsu, C.W., 2010. Critical factors for implementing green supply chain management practice: an empirical study of electrical and electronics industries in Taiwan. Manage. Res. Rev. 33 (6), 586-608.

Jabbour, C.J.C., 2010. Tecnologias ambientais: em busca de um significado. Rev. Adm. Púb. RAP 44 (3), 591-611.

Jabbour, A.B.L.S., Jabbour, C.J.C., 2013. Gestão Ambiental Nas Organizações. Atlas Publisher, São Paulo.

Jabbour, C.J.C., Neto, A.S., Gobbo, J.A., de Souza Ribeiro, M., de Sousa Jabbour, A.B.L., 2015. Eco-innovations in more sustainable supply chains for a low-carbon economy: a multiple case study of human critical success factors in Brazilian leading companies. Int. J. Prod. Econ. 164, 245-257.

Jabbour, C.J.C., de Sousa Jabbour, A.B.L., Govindan, K., De Freitas, T.P., Soubihia, D.F., Kannan, D., Latan, H., 2016. Barriers to the adoption of green operational practices at Brazilian companies: effects on green and operational performance. Int. J. Prod. Res. 54 (10), 3042-3058.

Jackson, S.E., Renwick, D.W.S., Jabbour, C.J.C., Muller-Camen, M., 2011. State-of-theart and future directions for green human resource management: introduction to the special issue. Z. Personal Forsch. Ger. J. Res. in Hum. Resour. Manag. 25 (2), 99-116.

Johansson, G., 2002. Success factors for integration of ecodesign in product development: a review of state of the art. Environ. Manag. Health 13 (1), 98-107.

Klassen, R.D., Whybark, D.C., 1999. The impact of environmental technologies on manufacturing performance. Acad. Manag. J. 42 (6), 599-615.

Kuehr, R., 2007. Environmental technologies-from misleading interpretations to an operational categorisation \& definition. J. Clean. Prod. 15 (13), 1316-1320.

Lam, P.T., Chan, E.H., Poon, C.S., Chau, C.K., Chun, K.P., 2010. Factors affecting the implementation of green specifications in construction. J. Environ. Manag. 91 (3), 654-661.

Le Bourhis, F., Kerbrat, O., Hascoët, J.Y., Mognol, P., 2013. Sustainable manufacturing: evaluation and modeling of environmental impacts in additive manufacturing. Int. J. Adv. Manuf. Technol. 69 (9-12), 1927-1939.

Leal Filho, W., Shiel, C., Paço, A., 2016. Implementing and operationalising integrative approaches to sustainability in higher education: the role of projectoriented learning. J. Clean. Prod. 133, 126-135.

Lin, C.Y., Ho, Y.H., 2011. Determinants of green practice adoption for logistics companies in China. J. Bus. Ethics 98 (1), 67-83.

Liston-Heyes, C., Brust, D.A.V., 2016. Environmental protection in environmentally 
reactive firms: lessons from corporate Argentina. J. Bus. Ethics 135 (2), 361-379.

Liu, Y., Srai, J.S., Evans, S., 2016. Environmental management: the role of supply chain capabilities in the auto sector. Supply Chain Manag. An Int. J. 21 (1), 1-19.

Longoni, A., Luzzini, D., Guerci, M., 2016. Deploying environmental management across functions: the relationship between green human resource management and green supply chain management. J. Bus. Ethics 1-15.

Mangla, S.K., Govindan, K., Luthra, S., 2016. Critical success factors for reverse logistics in Indian industries: a structural model. J. Clean. Prod. 129, 608-621.

De Medeiros, J.F., Ribeiro, J.L.D., Cortimiglia, M.N., 2014. Success factors for environmentally sustainable product innovation: a systematic literature review. J. Clean. Prod. 65, 76-86.

Pagell, M., Shevchenko, A., 2014. Why research in sustainable supply chain management should have no future. J. Supply Chain Manag. 50 (1), 44-55.

Pinto, J.K., Slevin, D.P., 1989. Critical success factors in R\&D projects. Res. Technol, Manag. 32 (1), 31-35.

Prajogo, D., KY Tang, A., Lai, K.H., 2014. The diffusion of environmental management system and its effect on environmental management practices. Int. J. Oper. Prod. Manag. 34 (5), 565-585.

Renwick, D.W., Jabbour, C.J., Muller-Camen, M., Redman, T., Wilkinson, A., 2016. Contemporary developments in Green (environmental) HRM scholarship. Int. J. Hum. Resour. Manag. 27 (2), 114-128.

Rockart, J.F., 1978. Chief executives define their own data needs. Harv. Bus. Rev. 57 (2), 81-93.

Sarkis, J., Zhu, Q., Lai, K., 2011. An organizational theoretic review of green supply chain management literature. Int. J. Prod. Econ. 130 (1), 1-15.

Shrivastava, P., 1995. Environmental technologies and competitive advantage. Strat Manag. J. 16 (S1), 183-200.

Soo Wee, Y., Quazi, H.A., 2005. Development and validation of critical factors of environmental management. Ind. Manag. Data Syst. 105 (1), 96-114.

Subramanian, N. Gunasekaran, A., Abdulahman, M., Liu, C., 2013. Factors for implementing end-of-life reverse logistics in the Chinese manufacturing sector. Int. J. Sustain. Dev. World Ecol. 21 (3), 235-245.

Teixeira, A.A., Jabbour, C.J.C., Jabbour, A.B.L.S., 2012. Relationship between green management and environmental training in companies located in Brazil: a theoretical framework and case studies. Int. J. Prod. Econ. 140, 318-329.

Tiwari, M.K., Chang, P.C., Choudhary, A., 2015. Carbon-efficient production, supply chains and logistics. Int. J. Prod. Econ. 164, 193-196.

Umble, E.J., Haft, R.R., Umble, M.M., 2003. Enterprise resource planning: implementation procedures and critical success factors. Eur. J. Oper. Res. 146 (2) $241-257$.

Vachon, S., Klassen, R., 2007. Supply chain management and environmental technologies: the role of integration. Int. J. Prod. Res. 45 (2), 401-423.

Walker, P.H., Seuring, P.S., Sarkis, P.J., Klassen, P.R., 2014. Sustainable operations management: recent trends and future directions. Int. J. Oper. Prod. Manag. 34 (5).

Wong, C.W., Wong, C.Y., Boon-itt, S., 2013. Green service practices: performance implications and the role of environmental management systems. Serv. Sci. 5 (1), 69-84.

Yusliza, M.-Y., Nur Zahiyah, O., Yudi, F., Azlan, A., Lilis, S., Ramayah, T., 2015. Conceptualization of green human resource management: an exploratory study from Malaysian-based multinational companies. Int. J. Bus. Manag. Econ. Res. 6 (3), 158-166.

Zutshi, A., Sohal, A., 2004. Adoption and maintenance of environmental management systems: critical success factors. Manag. Environ. Qual. Int. J. 15 (4) 399-419. 